Original Research Paper

\title{
The Manifestation of the Discrete and Continuous Types of Bioelectric Control of Natural Locomotion at the Over-Five Age
}

\author{
Kazbek Chermit, Anatoliy Zabolotniy and Angelina Shakhanova \\ Adyghe State University (AGU), Maikop, Russian Federation
}

\author{
Article history \\ Received: $21-10-2015$ \\ Revised: 10-4-2016 \\ Accepted: $25-5-2016$ \\ Corresponding Author: \\ Angelina Shakhanova \\ Adyghe State University \\ (AGU), Maikop, Russian \\ Federation \\ Email: nisadgu@yandex.ru
}

\begin{abstract}
The concept of physiology of activity by N.A. Bernstein, developed on the grounds of in-depth theoretical and empirical analysis of natural human locomotion, served as a basis for understanding the target determination of human behavior, the mechanisms of motor skills formation and levels of building movements. Scientific and technological progress has determined the emergence of new methods for registration of natural human locomotion parameters, complementing Bernstein's concept with new structures. The method of interference surface electromyogram based on the "Neuro-MEP" computer system of the Neurosoft Company (Ivanovo, Russia) was used to study the indicators of signal implementation amplitude and frequency, as well as electromyogram patterns of shank, thigh and back muscles during squatting by 5-6-yearold children. The dominant types of patterns were determined. It has been found that in the study of muscle groups, the electromyogram burst waveform dominates at the age of 5 years and the monophasic waveform dominates at the age of 6 years. Based on the analysis of the content of obtained electromyograms, we justified the discrete and continuous type of bioelectric control. The discrete type dominates at the age of 5 years. The main criterion of its manifestation is the record of the EMG burst waveform. The continuous type of bioelectric control dominates at the age of 6 against the EMG monophasic waveform recording. It has been revealed that formation of the established types of bioelectric control of the muscle groups under study is subject to the laws of heterochrony and heterotrophy.
\end{abstract}

Keywords: Electromyography, Sensory Corrections, Bioelectric Control, Motor Function

\section{Introduction}

Movements of a human, representing motor actions implementing the human motor functions are defined as natural [according to the traditional opinion first formulated by Anokhin (1975), these include lying down, sitting, squatting, crawling, standing and body motions such as walking, running, jogging, swimming, jumping, climbing, clambering, etc.]. A movement, the main task of which is to move the human body, is defined as a loco motor movement and those that are natural for the human species, such as walking, running, jumping, swimming, squatting, etc. are related to basic natural locomotion. The implementation of the principle of sensory corrections of the operation of skeletal muscles during natural locomotion control is determined by the receipt and processing of sensory signals about the parameters of muscle contractions. Sensory signals from the position of N.A. Bernstein are integrated into one afferent flow specific for each level of movements building, its re-encoding in the central nervous system determines the manifestation of correction signals of the skeletal muscles functioning (Bernstein, 1947). This mechanism allows accumulating sensory experience, which is the basis for consolidation and provision of the motor skill. In this regard, the study of the formation and perfection of the mechanism of implementation of sensory corrections in the process of natural locomotion formation is relevant for understanding the mechanisms of the human motor function control. An objective method to obtain information about changes in the operation of skeletal muscles is electromyography (Andersson et al., 
1997; Melchiorri and Rainoldi, 2011; Urbanek and Van der Smagt, 2016; Guzmán-Venegas et al., 2016; Murray et al., 2016; Pagé et al., 2016; Jones et al., 2016; Maenhout et al., 2016; Stewart and Gregory, 2016; Charissou et al., 2016; Inada et al., 2016; Stein et al., 2016). The study of the surface EMG of masters of sport in powerlifting in previous studies allowed establishing the changes in the pattern types, parameters and the ratio of volumes of the bioelectric activity of the studied muscle groups when doing squats with different weights (Chermit et al., 2011). The data show that the expression of sensory corrections changes the nature of the bioelectric control. However, the formation of the basic principles of the bioelectric control of natural locomotion takes place long before the start of sports activities, that is, in the earlier period of ontogenesis. In this regard, the parameters of the bioelectric activity in the process of squats performed by 5-6year-old children were studied. This age is a period of intensive development of natural locomotion.

\section{Methodology}

The method of interference surface electromyogram based on the "Neuro-MEP" computer system of the Neurosoft Company (Ivanovo, Russia) was used to study the indicators of signal implementation amplitude and frequency, as well as electromyogram patterns of shank, thigh and back muscles during squatting by 5-6-year-old children. To determine the age peculiarities of bioelectric motion characteristics the midday data were compared with the results of similar studies of athletes. The study was conducted at the premises of the "Health" Center of the Adyghe State University by recording the surface electromyogram (EMG) on the basis of "Neuro-MEP", multi-function computer system, of the Neurosoft Company. Bipolar disc electrodes with electrode spacing of $2 \mathrm{~cm}$ were used to register EMG. They were positioned on the back in the lumbar region along of the fibers of erector spinae muscle; on the thigh-along the rectus femoris center; and in the shank area-in the lower part of the gastrocnemius muscle. The impedance under the electrodes ranged from 4 to $8 \mathrm{ohms}$. The experiment involved 50 practically healthy children aged 5-6 years participating on a voluntary basis and upon the prior consent of parents.

The studies were conducted before noon (9:00-12:00 $\mathrm{AM})$ at a comfort temperature $\left(18-20^{\circ} \mathrm{C}\right)$.

\section{Results}

Studying the patterns of the obtained electromyograms revealed that this age is characterized by the preferential expression of two types of patterns: EMG burst waveform and EMG monophasic waveform (Fig. 1 and 2).
Manifestation of the EMG burst waveform is more typical of children aged five. This EMG type was registered in $62.3 \%$ of the tested persons for the back muscles, in $67.1 \%$ for the thigh muscles and $71 \%$ for the shank muscles. By the age of six, the share of the EMG burst waveform manifestations is reduced, while the manifestations of the EMG monophasic waveform increase (Table 1). Thus, the manifestation of the EMG monophasic waveform for the back muscles increases from 32.1 to $68.9 \%(p \leq 0.001)$. The data characterizing the change of the dominant EMG type on the thigh and shank muscles are shown in Table 1.

It should be noted that the EMG burst waveform is characterized by sharp bursts of bioelectric activity. In accordance with the classification of the EMG patterns that we have developed (Chermit et al., 2011), the obtained high-amplitude bursts of bioelectric activity characterize the speed and power nature of the skeletal muscles' functioning. However, it was not defined by the conditions of testing. Children choose themselves the most natural way to perform the test task. In this regard, the speed and power mode of skeletal muscles' functioning manifests itself in children as the dominant method of performing a motor action. At the motor units contraction in the speed and power mode, a series of pulses is followed by signaling block (bioelectric silence), characterized by no feedback from the central nervous system. At this time, muscle fibers contract at a high speed without any control action. These features of motor units' contraction determine the discrete nature of sensory corrections. Moreover, the higher the rate of motor units contractions, the more discrete this mechanism. The transition by the age of six from the burst to monophasic waveform of bioelectric activity determines the formation of sustainable bioelectric control. Disabling the signal blocking and activation of the mechanism for implementing the feedback evidences the transition from the discrete to continuous type of sensory corrections, which allows for more precise correlation of intramuscular and intermuscular coordination mechanisms. In the kinematic structure, it manifests itself as the formation of a stable order of angular movements, at which the order of the joints' angular movements at their extension is reverse to their bending angular movements order. We have determined this previously in the course of the research of the kinematic characteristics of squats.

The change in the type of control occurs in a heterotrophic manner, as evidenced by the uneven rate of increase in the manifestation of the EMG monophasic waveform of the studied muscle groups. For example, between five and six years of age, the share of the monophasic waveform of the EMG of back muscles in the studied group increased by $32.9 \%$ (Fig. 3), which was significantly higher $(\mathrm{p} \leq 0.05)$ than the increase in this indicator for the thigh muscles $(19.3 \%)$ and shank muscles $(15.6 \%)$. 


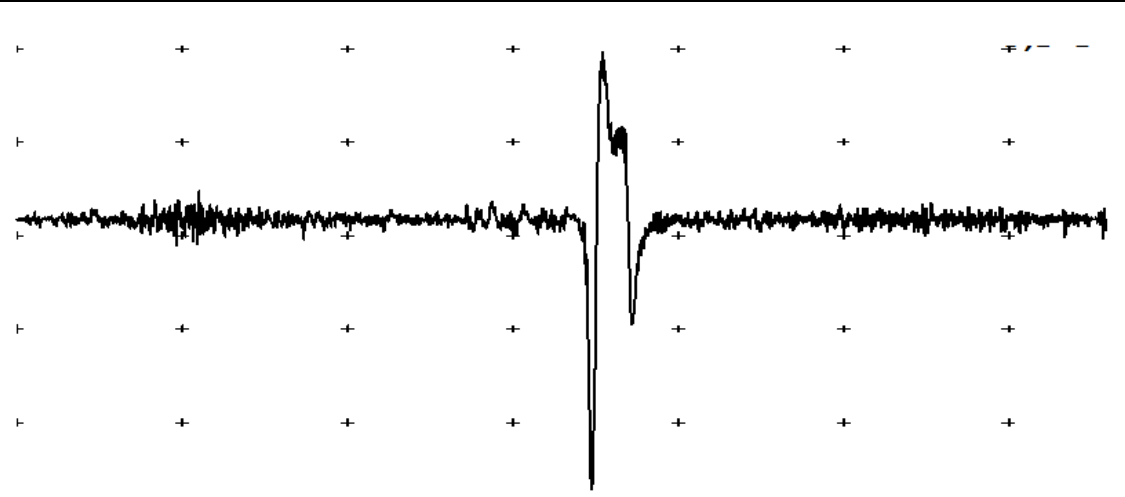

Fig. 1. The EMG burst waveform of the thigh muscles of children aged 5 years

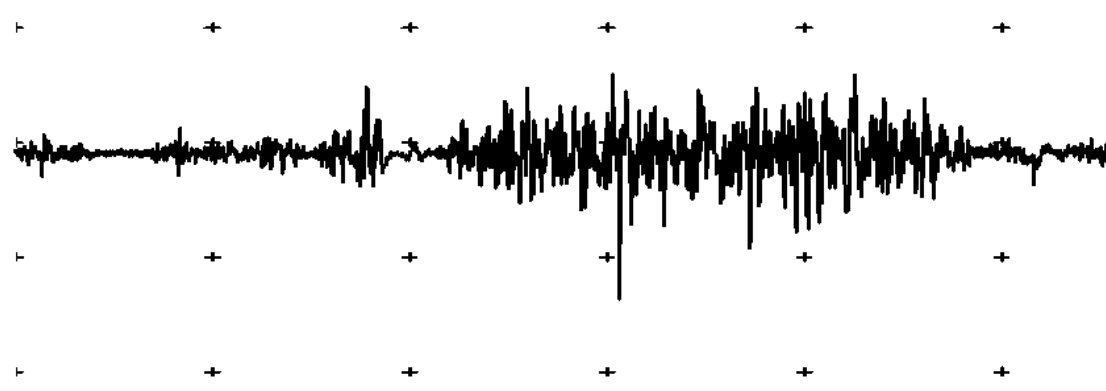

Fig. 2. The EMG monophasic waveform of the thigh muscles of children aged 6 years

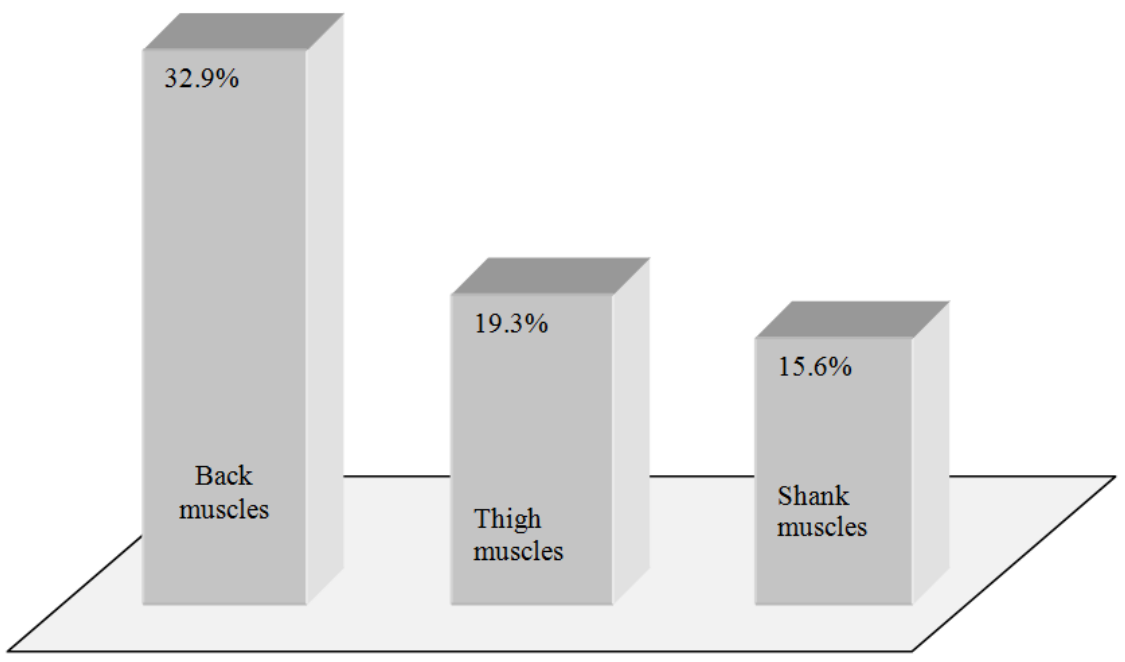

Fig. 3. The increasing manifestations of the monophasic waveform of the electromyogram of the back, thigh and shank muscles between five and six years of age

The findings suggest that from 5 to 6 years of age, the mechanisms of continuous control of movements (the main criterion of which is the manifestation of the EMG monophasic waveform) are most intensively formed in the regulation of the back muscles, while the formation of the mechanisms of continuous control of the thigh and shank proceeds less intensively. We must assume that this happens at a later stage of ontogenesis. This conclusion is consistent with Hay (1979) of the age-specific development of voluntary movements in children, which found that in 5year-old children, the system of programming and low importance of sensory corrections prevails. By the age of 7 years, according to the author, the control of movements involves the system of correction and monitoring. 
Table 1. The change in the ratio of the EMG types in the shank, thigh and back of children aged 5 and 6 when performing squats

\begin{tabular}{|c|c|c|c|c|c|c|}
\hline \multirow[b]{3}{*}{ Muscle groups } & \multicolumn{3}{|l|}{ Age } & \multicolumn{3}{|c|}{$\begin{array}{l}\text { The significance of differences by the } \\
\text { Fischer's angular transformation } \varphi\end{array}$} \\
\hline & \multicolumn{3}{|l|}{5 years old } & \multicolumn{3}{|l|}{6 years old } \\
\hline & $\begin{array}{l}\text { The share of } \\
\text { the EMG burst } \\
\text { waveform } \\
\text { manifestation }\end{array}$ & $\begin{array}{l}\text { The share } \\
\text { of the EMG } \\
\text { monophasic } \\
\text { waveform } \\
\text { manifestation }\end{array}$ & $\begin{array}{l}\text { The share of } \\
\text { the EMG burst } \\
\text { waveform } \\
\text { manifestation }\end{array}$ & $\begin{array}{l}\text { The share } \\
\text { of the EMG } \\
\text { monophasic } \\
\text { waveform } \\
\text { manifestation }\end{array}$ & $\begin{array}{l}\text { Between the } \\
\text { burst waveform } \\
\text { EMGs of } \\
\text { children } \\
\text { aged } 5 \text { and } 6\end{array}$ & $\begin{array}{l}\text { Between the } \\
\text { monophasic } \\
\text { waveform of } \\
\text { EMGs of children } \\
\text { aged } 5 \text { and } 6\end{array}$ \\
\hline Back muscles & $62.3 \%$ & $37.7 \%$ & $32.1 \%$ & $68.9 \%$ & $\mathrm{p} \leq 0.001$ & $\mathrm{p} \leq 0.001$ \\
\hline Thigh muscles & $67.1 \%$ & $32.9 \%$ & $47.8 \%$ & $52.2 \%$ & $\mathrm{p} \leq 0.05$ & $\mathrm{p} \leq 0.05$ \\
\hline Shank muscles & $71 \%$ & $29 \%$ & 55.4 & $44.6 \%$ & $\mathrm{p} \leq 0.05$ & $\mathrm{p} \leq 0.05$ \\
\hline
\end{tabular}

Table 2. Parameters of the bioelectric activity in the groups of children aged 5 and 6 at squatting

\begin{tabular}{|c|c|c|c|c|c|c|c|}
\hline \multirow[b]{2}{*}{ Muscle groups } & \multirow{2}{*}{$\begin{array}{l}\text { Parameters of } \\
\text { bioelectric } \\
\text { activity }\end{array}$} & \multirow[b]{2}{*}{5 years old } & \multirow[b]{2}{*}{6 years old } & \multirow{2}{*}{$\begin{array}{l}\text { Masters of sport } \\
\text { in powerlifting }\end{array}$} & \multicolumn{3}{|c|}{ Significance of differences } \\
\hline & & & & & Between 1-2 & Between 1-3 & Between 2-3 \\
\hline \multirow[t]{2}{*}{ Shank muscles } & EMG amplitude $(\mu \mathrm{V})$ & $346.08 \pm 73.1$ & $295.3 \pm 60$ & $160 \pm 30.4$ & $\mathrm{p} \geq 0.05$ & $\mathrm{p} \leq 0.01$ & $\mathrm{p} \leq 0.05$ \\
\hline & $\begin{array}{l}\text { EMG frequency } \\
\text { (times per second) }\end{array}$ & $40.4 \pm 12.1$ & $32.1 \pm 3.8$ & $20.7 \pm 5.1$ & $\mathrm{p} \geq 0.05$ & $\mathrm{p} \leq 0.01$ & $\mathrm{p} \leq 0.05$ \\
\hline \multirow[t]{2}{*}{ Thigh muscles } & EMG amplitude $(\mu \mathrm{V})$ & $214 \pm 63.2$ & $235.2 \pm 54$ & $369 \pm 70.3$ & $\mathrm{p} \geq 0.05$ & $\mathrm{p} \leq 0.05$ & $\mathrm{p} \leq 0.05$ \\
\hline & $\begin{array}{l}\text { EMG frequency } \\
\text { (times per second) }\end{array}$ & $19.4 \pm 4.1$ & $21.4 \pm 4.5$ & $75.2 \pm 31.5$ & $\mathrm{p} \geq 0.05$ & $\mathrm{p} \leq 0.05$ & $\mathrm{p} \leq 0.05$ \\
\hline \multirow[t]{2}{*}{ Back muscles } & EMG amplitude $(\mu \mathrm{V})$ & $72.2 \pm 15.3$ & $95.2 \pm 21$ & $185 \pm 35.1$ & $\mathrm{p} \geq 0.05$ & $\mathrm{p} \leq 0.05$ & $\mathrm{p} \leq 0.05$ \\
\hline & $\begin{array}{l}\text { EMG frequency } \\
\text { (times per second) }\end{array}$ & $12 \pm 3.1$ & $14 \pm 4.2$ & $22.1 \pm 6$ & $\mathrm{p} \geq 0.05$ & $\mathrm{p} \geq 0.05$ & $\mathrm{p} \geq 0.05$ \\
\hline
\end{tabular}

Thus, the over five age is a nodal period of ontogeny and formation of natural locomotion. The obtained data allow determining the required pedagogical influence on the development of motor skills of children aged 5 and 6 years. Thus, the pedagogical influence at the age of 5 years should target mastering new locomotion due to the predominance of the ability to program motor actions over the implementation of sensory corrections. The focus of pedagogical influence at the age of 6 years should be shifted from mastering new locomotion to improving the quality of implementation of the already formed locomotion, due to the formation of the capacity for the continuous implementation of sensory corrections.

The study of the parameters of the maximum amplitude and average frequency of the EMG signal in the course of squatting allows defining the absence of any significant $(p \leq 0.05)$ differences in these parameters of bioelectric activity in the groups of children aged 5 and 6 (Table 2). Thus, in the group of five-year-old children, the values of the maximum amplitude of the shank muscles signal make $346.08 \pm 73.1 \mu \mathrm{V}$ and the average frequency of the signal is $40.4 \pm 4$.1 times per second. In the group of 6year-old children, these values are $295.3 \pm 60 \mu \mathrm{V}$ and $32.1 \pm 3.8$ times per second, respectively. The parameters of the amplitude and frequency of the EMG signal for the shank and thigh muscles are given in Table 2.

The high variability of the sample in terms of the maximum amplitude of the signal does not allow determining, which of the muscle group sunder study shows the most intensive bioelectric activity. Therefore, this problem was solved by analyzing the individual data of each child. Thus, when comparing the mean values of the amplitude and the EMG signal frequency for the shank, thigh and back muscles, obtained during squatting, we managed to determine that $94 \%$ of the tested children aged five demonstrated significantly high $(p \leq 0.05)$ values of the maximum amplitude of the EMG signal for the shank muscles, while $6 \%$ demonstrated significantly high $(\mathrm{p} \leq 0.05)$ values of the maximum amplitude of the EMG signal for the thigh muscles. A similar situation is observed in the manifestation of the average frequency of the EMG signal, when the significantly high $(\mathrm{p} \leq 0.05)$ values of this indicator for the shank muscles are typical of $91 \%$ of the surveyed children and that for the thigh muscles were observed in $9 \%$ of the 5 -year-old children.

By the age of 6 years, the dominance of bioelectric activity of the shank muscles persists, as evidenced by the significantly high $(\mathrm{p} \leq 0.05)$ values of the maximum amplitude of the signal in $82 \%$ of the tested children and the average frequency of the signal in $76 \%$ of children aged 6 . The lowest parameters of the maximum amplitude and the average frequency of the signal in the groups of children aged 5 and 6 are typical of the back muscles.

Comparison of the parameters of the maximum amplitude and the frequency of the EMG signal obtained in the groups of children aged 5 and 6 with those obtained in the study of power lifters reveals that children are characterized by high values of these parameters of bioelectric activity of the shank muscles. For example, the 
maximum amplitude of the signal of shank muscles in power lifters is $160 \pm 30.4 \mu \mathrm{V}$ and in 5-year-old children $346.08 \pm 73.1 \mu \mathrm{V}(\mathrm{p} \leq 0.01)$. The parameters of bioelectric activity of the thigh muscles in the groups of children aged 5 and 6 were significantly lower $(p \leq 0.05)$ than in athletes. The average value of the maximum amplitude of the EMG signal for the thigh muscles in children aged 5 is $214 \pm 63.2$ $\mu \mathrm{V}$ and in athletes $-369 \pm 70.3 \mu \mathrm{V}$. Furthermore, in the 5year old children compared with athletes, the values of the maximum amplitude of the EMG signal for the back muscles are significantly lower $-72.2 \pm 15.3 \mu \mathrm{V}$ and $185 \pm 35.1 \mu \mathrm{V}$, respectively.

The only parameter of bioelectric activity, for which no significant differences among all groups of children and power lifters were found, is the average frequency per second of the EMG signal for the back muscles.

The study of the proportion of shares of bioelectric activity of the muscle groups under study in the mechanism of bioelectric control allows determining that in terms of the maximum amplitude of the EMG signal, the share of bioelectric activity of the shank muscles at the age of five is $55 \%$, thigh muscles $-34 \%$ and the shank muscles $-11 \%$ (Table 3). The shares of bioelectric activity of the maximum amplitude of the EMG signal do not change in childrenat the age of $\operatorname{six}(p \geq 0.05)$. The bioelectric activity of the shank muscles is $47 \%$, the thigh muscles $-38 \%$ and the back muscles $-15 \%$.

A similar situation is observed in the proportion of shares of bioelectric activity in terms of the average frequency of the EMG signal. For example, in the group of children aged five, the bioelectric activity of the shank muscles is $56 \%$, the thigh muscles $-27 \%$ and the back muscles $-17 \%$ (Table 4 ). No significant changes take place in the balance of shares of the bioelectric activity in terms of the average frequency of the EMG signal in the group of 6-year-old children compared with the group of children aged five. The bioelectric activity of the shank muscles is $47 \%$, the thigh muscles $-38 \%$ and the back muscles $-15 \%$ (Table 4 ).

The study of the share of bioelectric activity of the shank, thigh and back muscles during squatting by masters of sport in powerlifting allows finding the transformation of the bioelectric control parameters, as evidenced by the change in the share of the bioelectric activity of the shank, thigh and back muscles. For example, in terms of the maximum amplitude of the EMG signal, the ratio of shares of bioelectric activity of the studied muscle groups changed as follows: The proportion of the bioelectric activity of the shank in the mechanism of bioelectric control in athletes decreased compared with similar parameters of children aged 5 and 6 from 55 and 47 to $22 \%$, respectively (Table 3 ).

The share of bioelectric activity of the thigh muscles in athletes increased $(\mathrm{p} \leq 0.05)$ compared with that of children aged 5 from 34 to $52 \%$. At the same time, by the age of 6 years, the differences between the children and athletes' values of this indicator are not detected. The share of bioelectric activity of the back muscles in terms of the EMG signal amplitude in athletes compared with children aged 5 is significantly higher and equals to 11 and $26 \%$, respectively. By the age of six, the differences between the children and athletes' values of this indicator are not detected. A similar situation is observed in the study of the ratio of the bioelectric activity shares in terms of the average frequency of the EMG signal. The share of the bioelectric activity of the shank muscles in athletes compared with children aged 5 and 6 decreased from 56 and 47 to $17 \%$ (Table 4 ). The share of bioelectric activity of the thigh muscles in athletes increased $(\mathrm{p} \leq 0.001)$ compared with children aged 5 and 6 from 27 and 32 to $64 \%$, respectively. No significant differences in the proportion of shares of the bioelectric activity of the back muscles in terms of the average frequency of the EMG signal between the groups of children and athletes were determined.

Table 3. The proportion of shares of bioelectric activity by the values of the maximum EMG signal amplitude

\begin{tabular}{|c|c|c|c|c|c|c|}
\hline \multirow[b]{3}{*}{ Muscle groups } & \multicolumn{3}{|c|}{ Shares of bioelectric activity } & \multirow{2}{*}{\multicolumn{3}{|c|}{$\begin{array}{l}\text { Significance of differences by the } \varphi \text {-criterion-the } \\
\text { Fischer's angular transformation }\end{array}$}} \\
\hline & \multirow{2}{*}{$\begin{array}{l}1 \\
\text { Children } 5 \text { years } \\
\text { old } n=50(\%)\end{array}$} & \multirow{2}{*}{$\begin{array}{l}2 \\
\text { Children } 6 \text { years } \\
\text { old } n=50(\%)\end{array}$} & \multirow{2}{*}{$\begin{array}{l}3 \\
\text { Sportsmen } \\
\mathrm{n}=30(\%)\end{array}$} & & & \\
\hline & & & & $\begin{array}{l}\text { Between } \\
1 \text { and } 2\end{array}$ & $\begin{array}{l}\text { Between } \\
1 \text { and } 3\end{array}$ & $\begin{array}{l}\text { Between } \\
2 \text { and } 3\end{array}$ \\
\hline Shank muscles & 55 & 47 & 22 & $(\mathrm{p} \geq 0.05)$ & $(\mathrm{p} \leq 0.001)$ & $(\mathrm{p} \leq 0.001)$ \\
\hline Thigh muscles & 34 & 38 & 52 & $(\mathrm{p} \geq 0.05)$ & $(\mathrm{p} \leq 0.05)$ & $(\mathrm{p} \geq 0.05)$ \\
\hline Back muscles & 11 & 15 & 26 & $(\mathrm{p} \geq 0.05)$ & $(\mathrm{p} \leq 0.05)$ & $(\mathrm{p} \geq 0.05)$ \\
\hline
\end{tabular}

Table 4. The shares of bioelectric activity in terms of the average frequency of the EMG signal

\begin{tabular}{|c|c|c|c|c|c|c|}
\hline \multirow[b]{3}{*}{ Muscle groups } & \multicolumn{3}{|c|}{ Shares of bioelectric activity } & \multirow{2}{*}{\multicolumn{3}{|c|}{$\begin{array}{l}\text { Significance of differences by the } \varphi \text {-criterion-the } \\
\text { Fischer's angular transformation }\end{array}$}} \\
\hline & \multirow{2}{*}{$\begin{array}{l}1 \\
\text { Children } 5 \text { years } \\
\text { old } n=50(\%)\end{array}$} & \multirow{2}{*}{$\begin{array}{l}2 \\
\text { Children } 6 \text { years } \\
\text { old } n=50(\%)\end{array}$} & \multirow{2}{*}{$\begin{array}{l}3 \\
\text { Sportsmen } \\
n=30(\%)\end{array}$} & & & \\
\hline & & & & $\begin{array}{l}\text { Between } \\
1 \text { and } 2 \\
\end{array}$ & $\begin{array}{l}\text { Between } \\
1 \text { and } 3 \\
\end{array}$ & $\begin{array}{l}\text { Between } \\
2 \text { and } 3 \\
\end{array}$ \\
\hline Shank muscles & 56 & 47 & 17 & $(\mathrm{p} \geq 0.05)$ & $(\mathrm{p} \leq 0.001)$ & $(\mathrm{p} \leq 0.001)$ \\
\hline Thigh muscles & 27 & 32 & 64 & $(\mathrm{p} \geq 0.05)$ & $(\mathrm{p} \leq 0.001)$ & $(\mathrm{p} \leq 0.001)$ \\
\hline Back muscles & 17 & 21 & 19 & $(\mathrm{p} \geq 0.05)$ & $(\mathrm{p} \geq 0.05)$ & $(\mathrm{p} \geq 0.05)$ \\
\hline
\end{tabular}




\section{Discussion}

The obtained data allowed distinguishing two types of the motor functions control: Discrete and continuous. The discrete type dominates at the age of five. The main criterion of its manifestations is the registration of the EMG burst waveform. Domination of the continuous type of the impellent action control manifests itself by the age of six. The main criterion of its manifestation is the registration of the EMG monophasic waveform. The EMG monophasic waveform characterized by gradual increase and decrease in the bioelectric activity is one of the criteria of the quality of the impellent function control, at which sensory corrections are performed continuously.

The proportion of shares of the bioelectric activity of the thigh, shank and back muscles in terms of the maximum amplitude and average frequency of the EMG signal at the stage of formation of the mechanism of natural locomotion control and at the stage of athletic improvement leads to the conclusion that the implementation of bioelectric control of squats at the age of 5 and 6 years is performed with the predominant role of the bioelectric activity of the shank muscles. In the course of athletic improvement, there is a transformation of the bioelectric control, in the course of which the dominant role shifts to the bioelectric activity of the thigh muscles.

Improvement of the motor function in the process of sport training is determined by the functional improvement of the system ensuring the formation of the motor program and implementation of movements, as well as the improvement of the central mechanisms of organization and regulation of movements, which is implemented through the elimination of redundant degrees of freedom, limitation of the excessive afferentation, improvement of the selectivity and establishment of the effective interaction between different hierarchical levels of the movement control system. The parameters of the bioelectric control of muscle groups allow judging about the maturity of these mechanisms and the transformation of the bioelectric control parameters at the stages of ontogeny or in the process of athletic improvement-about the qualitative restructuring of the impellent action. For example, the decrease in the parameters of the bioelectric activity of the shank muscles in sportsmen compared to children evidences the decreasing redundancy of regulatory processes providing postural stability during squatting. Improving the mechanism of postural stability and the kinesthetic control functions creates conditions for increasing the activity of the muscle groups that provide basic angular movements in the kinematic chains of the musculoskeletal system, which, in particular at squatting, manifests itself as the increasing bioelectric activity of the thigh muscles providing angular movements of the knee joint. The determined transformation of the parameters of the bioelectric activity of the shank, thigh and back muscles providing the angular movements in the kinematic chains of the locomotor system when performing squats allows determining conditionally the specificity of operation for each component.

The shank muscles determine the interaction of the foot with the footing, playing an important role in the equilibrium control mechanism, as the result of the opposition to gravitation. The reduction in the bioelectric activity of this muscle group suggests stabilization of the regulatory mechanisms of the equilibrium control. The thigh muscles implement the movement in the knee joint, providing the greatest angular movements out of all elements of the kinematic chain. The back muscles play an important role in ensuring retention of the mass center inside the footing area.

It should be noted, that the instability of the coordination mechanisms of children aged 5 and 6 while squatting is confirmed by studies (Bukreeva et al., 1975). They stated that the biodynamics of children is distinguished by the presence of excessive fluctuations and non-uniformity of the parameters of speed and acceleration. However, the features that occur due to the imperfection of the mechanism of children's sensory corrections do not prevent them from mastering a great variety of movements, especially symmetrical movements of hands and feet. Thus, the dominance of the share of bioelectric activity of the shank muscles in the bioelectric control mechanism is an age-specific feature of the preschool age children's mastering of the squatting technique, which determines the imperfection of the mechanism of sensory corrections. In the further process of age-specific athletic development, the organization of natural locomotion changes substantially: The dominance of the system of motion programming is replaced by the dominance of the system of sensory corrections. This statement in the process of mastering squats is confirmed by the transformation of bioelectric control, which we have identified and which is based on the decreasing share of bioelectric activity of the shank muscles and the increasing share of the bioelectric activity of the thigh muscles in the system of bioelectric control.

\section{Conclusion}

The conducted research established the discrete and continuous types of bioelectric control of natural locomotion of over five children: 
- At the age of five, the discrete type prevails, the basic criterion of which is the manifestation of the EMG burst waveform, characterized by sudden bursts of the bioelectric activity and emergence of the signaling block indicating the absence of feedback from the central nervous system while contracting the locomotor units

- At the age of six, the continuous type prevails, the basic criterion of which is the manifestation of the EMG monophasic waveform, characterized by gradual increase and decrease of the bioelectric activity, absence of the signaling block and manifestation of continuous communication with the central nervous system while contracting the locomotor units

Between 5 and 6 years of age, the dominant type of bioelectric control changes in a heterotrophic way, as evidenced by the significant increase in the manifestations of the EMG monophasic waveform for the back muscles $(32.9 \%)$ compared with the increase in its manifestations in the electromyograms for thigh muscles (19.3\%) and shank muscles (15.6\%).

The manifestation of the EMG monophasic waveform is one of the criteria of quality of the locomotor function control, in which sensory corrections are implemented continuously when performing squats at the senior preschool age.

The bioelectric control of squats at the age of 5 and 6 years is performed with the dominant role of the bioelectric activity of the shank muscles. At the stage of athletic improvement, the transformation of the bioelectric control takes place, during which the dominant role shifts to the bioelectric activity of the thigh muscles.

\section{Acknowledgement}

We thank our unknown reviewers for their review and comments that greatly improved the manuscript.

\section{Author's Contributions}

Kazbek Chermit: Developed the conceptual idea and design of the research work and provided critical research reviewing for significant intellectual content.

Anatoliy Zabolotniy: Carried out the study, data collection of the study sample and writing the manuscript.

Angelina Shakhanova: Participated in the results analysis, contributed to the drafting of the article.

\section{Ethics}

The authors have no conflicts of interest in the development and publication of current research.

\section{References}

Andersson, E.A., J. Nilsson and A. Thorstensson, 1997. Intramuscular EMG from the hip flexor muscles during human locomotion. Acta Phys. Scand, 161: 361-370.

Anokhin, P.K., 1975. Essays in physiology of functional systems. Meditsina, Moscow.

Bernstein, N.A., 1947. On construction of movements. Medgiz, Moscow.

Bukreeva, D.P., S.A. Kosilov and A.P. Tambieva, 1975. Age peculiarities of cyclic movements of children and adolescents. Pedagogika, Moscow.

Charissou, C., L. Vigouroux, E. Berton and D. Amarantini, 2016. Fatigue- and training-related changes in 'beta' intermuscular interactions between agonist muscles. J. Electromyography Kinesiol., 27: 52-59. DOI: $10.1016 /$ j.jelekin.2016.02.002

Chermit, K.D., A.V. Shakhanova, A.G. Zabolotnii and A.A. Thagova, 2011. Electromyographic characteristic of squatting in powerlifting. Ser. Natural Sci., 4: 95-101.

Guzmán-Venegas, R.A., M.P. Bralic, J.J. Cordero, G. Cavada and O.F. Araneda, 2016. Concordance of the location of the innervation zone of the tibialis anterior muscle using voluntary and imposed contractions by electrostimulation. J. Electromyography Kinesiol., 27: 18-23.

DOI: 10.1016/j.jelekin.2016.01.002

Hay, L., 1979. Spatial-temporal analysis of movements in children: Motor programs versus feedback in the development of reaching. J. Mot. Behav., 11: 189-193. DOI: 10.1080/00222895.1979.10735187

Inada, T., F. Kaneko and T. Hayami, 2016 Effect of kinesthetic illusion induced by visual stimulation on muscular output function after short-term immobilization. J. Electromyography Kinesiol., 27: 66-72. DOI: 10.1016/j.jelekin.2016.01.006

Jones, A.A., G.A. Power and W. Herzog, 2016. History dependence of the electromyogram: Implications for isometric steady-state EMG parameters following a lengthening or shortening contraction. J. Electromyography Kinesiol., 27: 30-38. DOI: 10.1016/j.jelekin.2016.01.008

Maenhout, A., M. Benzoor, M. Werin and A. Cools, 2016. Scapular muscle activity in a variety of plyometric exercises. J. Electromyography Kinesiol., 27: 39-45. DOI: 10.1016/j.jelekin.2016.01.003

Melchiorri, G. and A. Rainoldi, 2011. Muscle fatigue induced by two different resistances: Elastic tubing versus weight machines. J. Electromyography Kinesiol., 21: 954-959. DOI: 10.1016/j.jelekin.2011.07.015 
Murray, M., B. Lange, S.S. Chreiteh, H.B. Olsen and B.R. Nørnberg et al., 2016. Neck and shoulder muscle activity and posture among helicopter pilots and crew-members during military helicopter flight. J. Electromyography Kinesiol., 27: 10-17. DOI: 10.1016/j.jelekin.2015.12.009

Pagé, I., F. Nougarou and M. Descarreaux, 2016. Neuromuscular response amplitude to mechanical stimulation using large-array surface electromyography in participants with and without chronic low back pain. J. Electromyography Kinesiol., 27: 24-29.

DOI: 10.1016/j.jelekin.2016.01.004
Stein, F., I. Kobor, U. Bogdahn and W.U. SchulteMattler, 2016. Toward the validation of a new method (MUNIX) for motor unit number assessment. J. Electromyography Kinesiol., 27: 73-77. DOI: 10.1016/j.jelekin.2016.02.001

Stewart, D.M. and D.E. Gregory, 2016. The use of intermittent trunk flexion to alleviate low back pain during prolonged standing. J. Electromyography Kinesiol., 27: 46-51. DOI: 10.1016/j.jelekin.2016.01.007

Urbanek, H. and P. Van der Smagt, 2016. iEMG: Imaging electromyography. J. Electromyography Kinesiol., 27: 1-9. DOI: 10.1016/j.jelekin.2016.01.001 